\title{
Role of surgery in the management of the metabolic syndrome
}

\author{
An Essay \\ submitted for partial fulfillment of master degree \\ in general surgery
}

By

Tamer Mohamed Said Abd El Baki

M.B., B.CH

\begin{abstract}
Under Supervision of
Professor Dr. Alaa Abbass Sabry

Professor of General Surgery

Faculty of Medicine - Ain Shams University

Dr. Hany Mohamed El-Barbary

Lecturer of General Surgery

Faculty of Medicine - Ain Shams University
\end{abstract}

Faculty of Medicine

Ain Shams University

2008 


\begin{abstract}
The Metabolic Syndrome is a complicated condition in which several aspects of normal metabolism are affected. it was found that bariatric surgery especially gastric bypass, biliopancertic diversion, vertical band gastroplasty is associated with significant effects on the metabolic aspect of the syndrome specially diabetes. clinical trials including patients with BMI from 30-35 (non obese patients) found that components metabolic syndrome markedly improve with surgical treatment, especially diabetes.

Conclusion: The future studies hopes that bariatric surgical procedures will be final solution for metabolic syndrome for both obese and non obese patient.
\end{abstract}

\section{Summary:}

The Metabolic Syndrome is a complicated condition in which several aspects of normal metabolism are affected. ${ }^{1}$

Recently metabolic syndrome is defined by International Diabetic Federation as: Central obesity (measured mainly by waist circumference), together with increase in fasting blood glucose level plus hypertension or hypertriglyceraldemia. ${ }^{2}$

Etiology of metabolic syndrome is multifactorial in which abnormality in adipose tissue metabolism is considered as a cornerstone in it's pathophysiology. There is increase level of non-esterified fatty acid in adipose tissue, which increase insulin resistance in the muscles and liver. It also secrets various types of adipokinies which also increase insulin resistance and acts as proinflammtory mediator with enhances ${ }^{3}$ atherosclerosis. Inherited genetic and environmental factors also play a role.

Previously the management of metabolic syndrome considered to be mainly medical through changing life style (exercise, stopping smoking, decrease fatty diet) and through treatment of complications (diabetes, hypertension and hyperlipidmia). ${ }^{4}$

Recently it was found that bariatric surgery is associated with significant effects on the metabolic aspect of the syndrome specially diabetes. ${ }^{5}$

Several bariatric surgical procedures have been introduced including restrictive, malabsorptive and combined techniques.

Malabsorptive bariatric surgery includes biliopancertic diversion which is done with or without duodenal switch. In BPD, the small bowel is divided to create a $200 \mathrm{~cm}$ long alimentary limb (from the stomach), with the bile and pancreatic juices passing through the remaining small bowel. The two limbs are connected to form a 50-cm long common limb of small intestine proximal to the ileocecal valve this acts by exclusion of the duodenum and jejnum which prevents full absorption of nutrients. ${ }^{6}$

Restrictive bariatric surgery as gastric banding by places a constricting ring around the stomach, below the gastro-oesphageal junction. The bands incorporate an inflatable balloon which can adjust the size of the ring, to regulate food intake and vertical band gastroplasty act mainly by decreasing gastric capacity to limit diet intake. ${ }^{7}$

Combined bariatric surgery as gastric bypass in this procedure, the stomach is divided into a small proximal gastric pouch and the remaining main stomach is bypassed, The small pouch is connected to the small bowel by a jejunal segment, a Roux limb acts by both mechanisms decreasing gastric capacity and excluding the duodenum which decreases nutrient absorption. ${ }^{8}$

Recently randomized clinical trials including patients with BMI from 30 - 35 (non obese patients) found that components metabolic syndrome markedly improve with surgical treatment, especially diabetes. ${ }^{9}$

These trails were based on:

1- Duodenal exclusion which decreases nutrient absorption (Done by Rubino). ${ }^{10}$

2- Neuroendocrine bases surgery (Digestive Adaption with Intestinal Reserve) which amplified post prandial Neuroendocrine response through decreasing post prandial Ghrelin and Resistin hormone by bypassing the forgut and increasing nutrient delivery to the hindgut which increase, Peptide YY3 and Glucagon-like peptide 1 hormone. ${ }^{11}$ 


\section{References:}

1- Alberti K, Zimmet P: Definition, diagnosis and classification of diabetes mellitus and its complications. Part 1: Diagnosis and classification of diabetes mellitus provisional report of a WHO consultation. Diabet Med 1998; 15: 539-553.

2- Einhorn D, Reaven G, Cobin R, et al: American College of Endocrinology position statement on the insulin resistance syndrome. Endocr Pract 2003; 9: 237-252.

3- Miranda PJ, Ralph A, et al: Metabolic syndrome mechanism and definition, pathophsyologiy: American Heart Journal 2005; 149(1): 33-45.

4- Liberopoulos E, Mikhailidis D, Elisaf MS: Diagnosis and management of the metabolic syndrome in obesity. Obesity Reviews 2005; 6(4): 283-296.

5- Buchwald H, Avidor Y, Braunwald E, et al: Bariatric surgery: A systematic review and meta-analysis. JAMA 2004; 292: 17241737.
6- Scopinaro N, Gianetta E, Civalleri D, et al: Bilio-pancreatic bypass for obesity: II. Initial experience in man. Br J Surg 2000; 66: 618-620.

7- Printen K, Mason E: Gastric surgery for relief of morbid obesity. Arch Surg 2000; 106: 428-431.

8- Sundbom M, Mardh E, Mardh S, et al: Reduction in serumpepsinogen I after Rouxen-Y gastric bypass. J Gastroin- test Surg 2003; 7: 529-535.

9- McTigue K, Harris R, Hemphill B, et al: Ann Intern Med 2003; 139: 933-949.

10-Rubino F, Jacques M: Effect of Duodenal Jejunal Exclusion in a Non obese Animal Model of Type 2 Diabetes. Ann Surg 2004; 239(1): 1-11.

11-Sérgio T, Carlos E, Manoel C, et al: Digestive adaptation with intestinal reserve: A neuroendocrine based operation for morbid obesity. Obesity Surgery 2006; 16(10). 


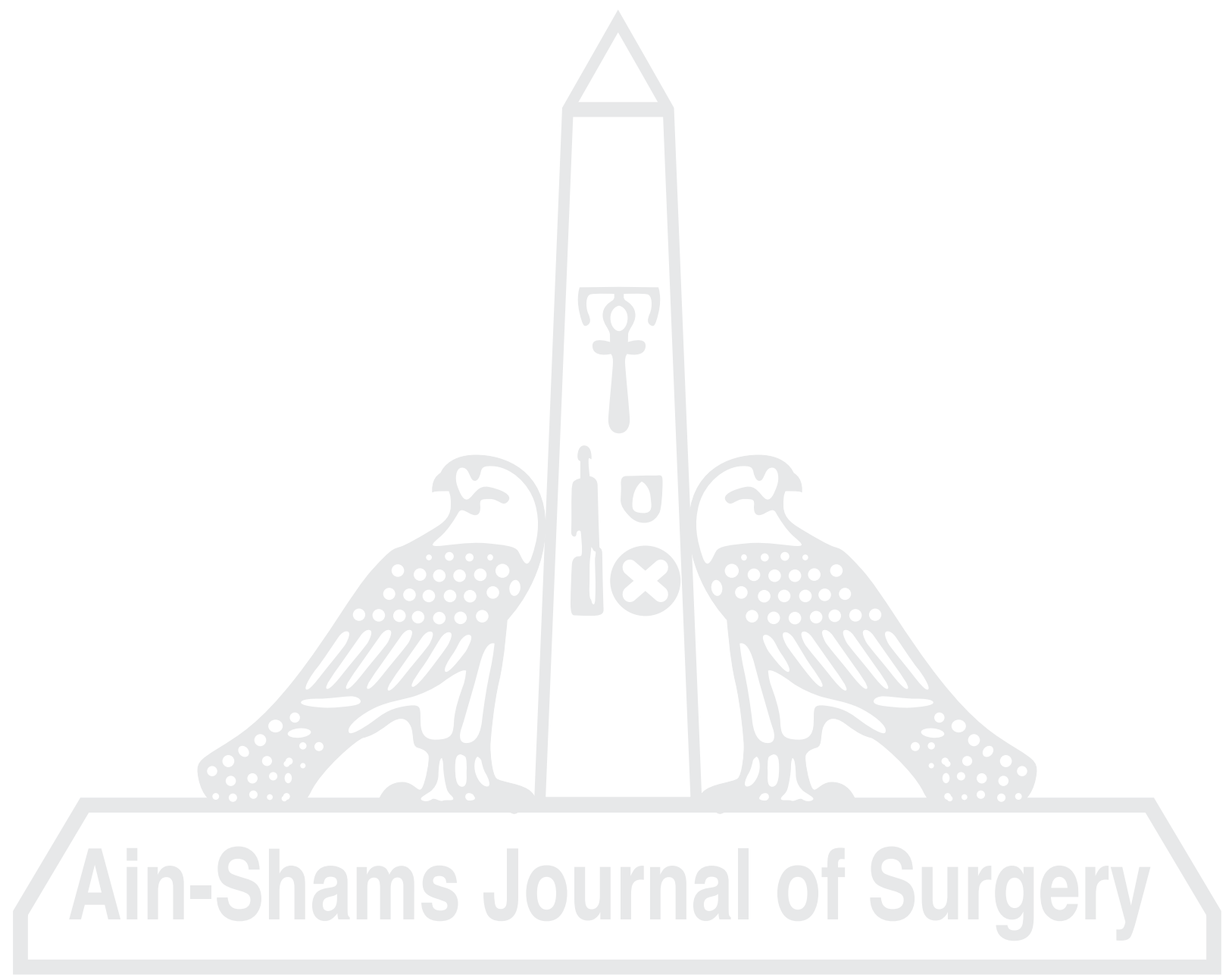

